\title{
Prevention of obstetric hemorrhages
}

\section{Bapayeva Gauri' ${ }^{1}$, Kulbayeva Saltanat ${ }^{2}$}

${ }^{1}$ Department of obstetrics and gynecolo, National research center for maternal and child health of the corporate fund «UMC», Astana, Kazakhstan

${ }^{2}$ South Kazakhstan State Pharmaceutical Academy, Shymkent, Kazakhstan

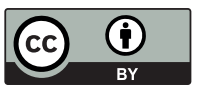

This work is licensed under a

Creative Commons Attribution 4.0 International License

J CLIN MED KAZ 2017; 3(45 SUPPL 3):125-127 Corresponding author: Бапаева Г.Б., отдел акушерства и гинекологии, Национальный научный центр материнства и детства корпоративного фонда «University Medical Center». Адрес: ул.Туран 32, Астана, Казахстан. Телефон: 8-7172-70-44-72,

E-mail: gauri.bapayeva@gmail.com

\section{ABSTRACT}

Obstetric bleeding is an urgent problem in modern obstetric. It remains one of the main causes of maternal mortality. The article presents a literature review of world dates on the management of the third stage of labor, measures taken to prevent postpartum hemorrhage.

Key words: postpartum hemorrhage, prevention, third stage of labor.

\section{ТҰЖЫРЫМДАМА}

АКУШЕРЛІК ҚАН КЕТУЛЕРДІН АЛДЫН-АЛУ(ӘДЕБИ ШОЛУ)

Бапаева Г.Б. ${ }^{1}$, Кулбаева С.Н. ${ }^{2}$

'Акушерлік және гинекология бөлімі, «UMC» корпоративтік қорының Ана мен бала ұлттық ғылыми орталығы, Астана, Қазакстан

${ }^{2}$ Оңтүстік-қазақстан мемлекеттік фарацевтика академиясы, Шымкент, Қазақстан

Акушерлік қан кетулер қазрігі денсаулық сақтаудың өзекті мәселелері болып табылады. Ол ана өлім-жітімінің негізгі себептерінің бірі болып қалып отыр. Мақалада босанудың үшінші кезеңін жүргізу бойынша, босанғаннан кейінгі қан кетуді алдын-алу мақсатында жүргізілетін шаралардың әлемдік мәліметтерінен әдеби шолу берілген.

Маңызды сөздер: босанғаннан кейінгі қан кетулер, алдын-алу, босанудың үшінші кезеңі.

PE3ЮME

\section{ПРОФИЛАКТИКА АКУШЕРСКИХ КРОВОТЕЧЕНИЙ (ЛИТЕРАТУР-}

НЫЙ ОБЗОР)

\section{Бапаева Г.Б. ${ }^{1}$, Кулбаева С.Н. ${ }^{2}$}

1Отдел акушерства и гинекологии, Национальный научный центр материнства и детства корпоративного фонда «UMC», г. Астана, Казахстан

2Южно-казахстанская государственная фармацевтическая академия, г. Шымкент, Казахстан

Акушерские кровотечения является актуальной проблемой в современном здравоохранении. Они остаются одной из основных причин материнской смертности. В статье представлен литературный обзор мировой литературы оведении третьего периода родов, мероприятиях, проводимых с целью профилактики послеродового кровотечения.

Ключевые слова: послеродовыекровотечения, профилактика, третий период родов.

\section{Введение}

Одним из основных методов профилактики акушерских кровотечений на сегодняшний день в последовом и раннем послеродовом периодах является правильное ведение третьего периода родов. В странах дальнего и ближнего зарубежья на протяжении последних лет ведутся дискуссии о целесообразности выжидательного или активного ведения третьего периода родов.

Активное ведение последового периода родов, по определению FIGO (International Federationof Gynecology and Obstetrics) и ICM (International Confederation of Midwives) подразумевает введение утеротонических препаратов с последующими контролируемыми тракциями за пуповину и массаж матки [1,2]. По данным рандомизированного контролируемого исследования, проведенного в Швеции (1802 женщины), при активном ведении третьего периода родов кровопотеря была меньше по сравнению с выжидательной тактикой [3]. В Казахстане также практикуется активное ведение третьего периода родов [4] и мониторинг за родильницей в раннем послеродовом периоде, что снижает вероятность развития послеродовых кровотечений в $2-2,5$ раза.

Имеется понятие выжидательно-активной тактики, при котором ожидают признаки отделения последа и выделяют уже отделившуюся плаценту. При этом с конца II периода родов устанавливают внутривенную систему с использованием катетеризации периферической вены, проводят профилактику кровотечения метил-эргометрином в момент прорезывания теменных бугров, головки плода, осуществляют бережное ведение III периода родов. Такая тактика снижает частоту послеродового кровотечения, потребность в переливании крови и дополнительных дозах утеротоников, сокращает длительность третьего периода [5], не увеличивая такие осложнения, как повышение артериального давления, ручное отделение плаценты, выворот матки, отрыв пуповины. 
Для предотвращения послеродового кровотечения на протяжении длительного времени используются утеротонические средства, что позволяет снизить материнскую смертность на 40\% [6] и на 60\% снизить риск развития послеродового кровотечения. При этом необходимость назначения утеротоников с лечебной целью уменьшается на 70\% [7], частота кровотечений у пациенток группы риска (крупный плод, многоплодие, многоводие, высокий паритет, аномалии родовой деятельности) уменьшается с 19,3\% до 10-13,4\%, а объем кровопотери в раннем послеродовом периоде - на 70-100 мл. Однако выбор препарата и метода его введения остается дискуссионным [8]. Различные исследователи предлагают разные схемы введения утеротоников.

Так, по методу 3.Н. Якубовой вводится 0,5 мл окситоцина в шприце с 20 мл 5\%глюкозы внутривенно очень медленно в III периоде родов после рождения плода и пережатия пуповины. После рождения последа 1,5 мл окситоцина вводятся внутримышечно [9]. Другие авторы предлагают использовать в группах высокого риска иные схемы:

- внутривенное капельное введение 5 ЕД окситоцина, растворенного в 400 мл физиологического раствора, начиная с конца второго периода родов, включая последовый период и 2 часа раннего послеродового периода [10];

- струйное введение 5 ЕД окситоцина (или 1 мл метилэргометрина) в 20 мл физиологического раствора с последующим капельным введением раствора простагландина F2а в течение 2-х часов [11].

Более свежий обзор Кокрана обращает внимание на применение с целью профилактики эргометрин-окситоцина вместо различных доз окситоцина в третьем периоде родов [12], сюда были включены 6 исследований. Обзор выявил, что эргометрин-окситоцин (синтометрин) как и окситоцин (5 ЕД и 10 ЕД), имеет такую же эффективность в профилактике кровотечений в после-родовом периоде свыше 1000 мл (синтометрин против любой дозы окситоцина: ОР - 0.78; 95\%; ДИ: 0.58-1.03; синтометрин против 5 ЕД окситоцина: ОР - 0.14; 95\%; ДИ: 0.00-6.85; синтометрин против окситоцина 10 ЕД: ОР - 0.78; 95\%; ДИ: 0.59-1.04).

В четырех рандомизированных исследованиях было проведено сравнение различных утеротонических препаратов для профилактики послеродовых кровотечений среди женщин родоразрешенным путем операции Кесарево сечением [13]. Оценка доказательств от этих исследований [14] позволила рекомендовать окситоцин 5 ЕД в виде медленной внутривенной инъекции для профилактики кровотечения после операции кесарево сечение. Значительно больше времени действует аналог окситоцина карбетоцин.

Известно, что окситоцин и метилэргометрин нестабильны при комнатной температуре и поэтому требуют специальной температуры и освещенности хранения [15]. Кроме того, эти препараты должны быть введены парентерально. В связи с этим, в последние годы широкое распространение в профилактикеи лечении акушерских кровотечений получил мизопростол с учетом его сокращающих матку свойств, простоты в использовании (перорально, вагинально или ректально), относительно низких затрат и стабильности при высоких температурах [16].

Кокрановский обзор рассмотрел эффективность применения простагландинов с целью профилактики послеродового кровотечения [17]. Он включил 32 исследования, которые показали, что обычные введенные утеротоники были предпочтительны, чем простагландины для рутинной профилактики, в то время как применение простагландинов в контексте акушерского кровотечения должно сосредоточиться на лечении, а не на профилактике. Тем не менее, в некоторых случаях, когда нет доступности к окситоцину (например, домашние роды), мизопростол уменьшает риск кровотечений.

Женщинам групп риска по кровотечению смешанного генеза (гипотоническому и коагулопатическому) целесообразно назначение ингибиторов протеаз, то есть антифибринолитических средств, безопасность и эффективность которых подтверждена данными доказательной медицины. В систематическом обзоре Кокрана (2007) по результатам 211 рандомизированных контролируемых исследований (20781 участник) показано: ингибиторы фибринолиза значительно уменьшают объем кровопотери и потребность в трансфузиях, их использование не сопровождается повышением частоты тромботических осложнений и летальных исходов [18]. К таким средствам относятся три препарата: апротинин, эпсилон-аминокапроновая кислота и транексамовая кислота. В сравнительных исследованиях по эффективности транексамовой кислоты и апротинина достоверных отличий не выявлено, а анти-фибринолитическая активность транексамовой кислоты значительно превосходит (в 10-20 раз) эффективность эпсилон-аминокапроновой кислоты [19]. Помимо того, эпсилон-аминокапроновая кислота имеет ряд серьезных побочных эффектов, значительно ограничивающих ее применение. Достаточная профилактическая концентрация транексамовой кислоты в плазме составляет 30-50 мкг/л [20].

В настоящее время потребность в снижении частоты послеродовых кровотечений является актуальной задачей для акушерских стационаров. Внедрение партнерских родов, свободное положение роженицы, демедикализация родов, активное ведение третьего периода родов, раннее прикладывание новорожденного к груди являются эффективными мерами, способствующими уменьшению кровопотери в родах [21,22].

Для динамического последовательного сокращения частоты послеродовых кровотечений используются также такие инструменты, как совершенствование мониторинга в последовом и раннем послеродовом периоде, использование стандартизированных протоколов и профилактическое применение средств, оказывающих сокращающее действие на матку.

Имеются данные, что в постнатальном периоде Пабал способен увеличивать частоту и силу спонтанных сокращений матки [23].

После введения препарата начало интенсивной сократительной деятельности с мощными сокращениями матки достигается на протяжении 2 минут. Однократное введение 100 мкг препарата внутривенно после рождения ребенка достаточно для поддержания адекватной сократимости матки, с целью предотвращения атонии матки и чрезмерной кровопотери.

С.Ш. Исеновой и соавторами было доказано, чтоприменение однократной внутривенной инъекции препарата Пабал при родах через естественные родовые пути и при операции кесарево сечение способствует достижению максимального эффекта в поддержании тонуса матки и ограничении кровопотери. Данный препарат 
обладает выраженным утеротоническим действием на мышцы матки, удобен в применении, так как однократный внутривенный приём препарата исключает необходимость повторных инъекций альтернативных утеротоников, а также постинъекционных осложнений и может применяться для профилактики послеродовых и послеоперационных кровотечений у женщин высокой группы риска по развитию кровотечений[24].

Также можно особо отметить, что применение препарата Пабал способствует снижению хирургических методов остановки кровотечения, объема трансфузии препаратов крови и кровезаменителей и реанимационных мероприятий $[25,26]$.

Женщинамгруппвысокогорискапокоагулопатическому кровотечению (преэклампсия, АФС, заболевания печени, железодефицитная анемия тяжелой степени, врожденные коагулопатии с дефицитом плазменных факторов) некоторые авторы рекомендуют опережающее (профилактическое) введение СЗП в дозе 5 мл/кг в 1 периоде родов или во время операции кесарева сечения [10, с. 1-5]. Обязательным условием назначения трансфузии в этих случаях является доказанный факт потребления факторов свертывания (снижение уровня фибриногена до 3и менее г/л, падение концентрации тромбоцитов на $30 \%$ от исходного уровня, повышенная концентрация РФМК) [28].

\section{Выводы.}

Основываясь на сопоставимой эффективности, в связи с меньшей частотой и тяжестью побочных эффектов по сравнению с другими утеротоникамипредпочтительно применение окситоцина с целью профилактики послеродовых кровотечений.При невозможности использовать окситоцин, препаратом выбораможет быть мизопростол,который, учитывая его потенциальные побочные эффекты,следует применять подготовленными специалистами.

\section{Литература:}

1. Mercer J.S.,Midwifery J. Current best evidence: A review of the literature on umbilical cord clamping Women's Health. $2001 ;(46): 402-414$.

2. Midwifery J. Joint statement: management of the third stage of labour to prevent post-partum hemorrhage Women's Health 2004; (49):76-77.

3. Jangsten E.,MattssonL.A.,Lyckestam I. et al.A comparison of active management and expectant management of the third stage of labour: a Swedish randomized controlled trial BJOG. 2011; (118-3):362-369.

4. Osnovnye klinicheskie protokoly i prikazy MZ RK po akusherstvu i neonatalogii [in Russian]. Astana, $2015 ; 17$.

5. Mc. Cormick M.L.,SanghviH.C., KinzieB., McIntosh N. Preventing postpartum hemorrhage in low-resource settings Int. J. Gynecol. Obstet. 2002; (77):267-275.

6. Suellen Miller,Lester Felicia, Paul Hensleigh Prevention and Treatment ofPostpartum Hemorrhage: New Advances for, LowResource Settings. J. Midwifery Women's Health.2004; (4):49.

7. Elbourne D.R.,PrendivilleW.J.,Carroli G. et al.Prophylactic use of oxytocin in the third stage of labour The Cochrane Database of Systematic Reviews. 2001;(4): 112-114.

8. Sursyakov V.A., Kurtser M.A., Panina O.B. Effektivnost' profilakticheskikh meropriyatii u rodil'nits gruppriska poslerodovykh kr

9. ovotechenii (The effectiveness of preventive measures in the parturients at risk of postpartum haemorrhage) [in Russian] Vestnik RGMU. 2005; 5 (44):36-42.

10. French L. Prevention andtreatment of postpartumendometritisCurr. WomensHealth Rep. 2003;(3-4):274-279.

11. Mal'tseva L.I., Zefirova T.P. Profilaktika I lechenie posle rodovykh akusherskikh krovotechenii(Prevention and treatment of postpartum obstetric hemorrhages) [in Russian].Informatsionnoepis'mo. 2009;5. 